\title{
Intrinsic vs Extrinsic Motivation as Drivers for Early Engagement in Research by Medical Students
}

This article was published in the following Dove Press journal:

Advances in Medical Education and Practice

\author{
Yassar Alamri iD ${ }^{1,2}$ \\ Erik Monasterio ${ }^{3}$ \\ Lutz Beckert (iD) ${ }^{2}$ \\ Tim J Wilkinson (D) 2,4 \\ 'Department of General Medicine, \\ Canterbury District Health Board, \\ Christchurch, New Zealand; \\ ${ }^{2}$ Department of Medicine, University of \\ Otago, Christchurch, New Zealand; \\ ${ }^{3}$ Department of Psychological Medicine, \\ Canterbury District Health Board, \\ Christchurch, New Zealand; ${ }^{4}$ Medical \\ Education Unit, University of Otago, \\ Christchurch, New Zealand
}

Background: A student's motivation is a key factor in their success in undertaking an education endeavour. However, how this relates to involvement in research by medical students is unclear.

Methods: An electronic questionnaire was sent to all medical students at our institution. To ascertain students' motivation to undertake research, they were asked an open-ended question to describe the single major factor that would encourage them to get involved in research as a medical student. A framework of self-determination theory was used to deductively code the responses as intrinsic motivation ("IM"; e.g., interest/passion) or extrinsic motivation ("EM"; e.g. improving $\mathrm{CV})$. The two groups were then contrasted in relation to their research engagement.

Results: A total of 348 students were included in the survey, of whom 204 were coded as IM responses, and 144 were coded as EM responses. Students who engaged in extra-curricular research activities were more likely to report an underlying EM (48\% vs 36\%, $p=0.03)$. They were also older $(23.7 \pm 3.5$ vs $21.9 \pm 3.7, p=0.005)$, and more likely to have completed a prior research degree $(15 \%$ vs $3 \%, p=0.01)$.

Conclusion: In this study, EM was a bigger influencer on research involvement by medical students than IM. Future studies should explore promoters of IM, and include longitudinal data in order to assess whether EM students continue to be involved in research long-term. Keywords: motivation, medical education and training, statistical and research methods

\section{Background}

Interest and involvement in research activities by medical students vary widelysometimes even within the same university. ${ }^{1}$ The gamut of benefits of early research engagement by medical students - including improved critical thinking, higher likelihood of remaining involved in research in the future, as well as being associated with later academic success - are well-described in the literature. ${ }^{1}$ What drives some students to engage in scholarly endeavours is probably multifaceted. However, the student's underlying motivation likely plays a significant role. $^{2}$

Examining students' motivation is being increasingly seen as important in understanding the effectiveness of educational interventions. ${ }^{3}$ Motivation can be thought of as one's desire for (or aversion from) an outcome, with varying underlying purpose(s) which make the pursuit of the outcome more or less likely. Using self-determination theory ${ }^{4}$ as a conceptual framework, it posits a distinction between intrinsic and extrinsic forms of motivation-both of which contribute to the underpinning of one's behaviour. Intrinsic motivation (IM) denotes the notion that an activity is undertaken because of its inherent enjoyment and excitement. Extrinsic motivation (EM), on the other hand, refers to doing an activity due to
Correspondence: Yassar Alamri

Canterbury District Health Board, 2

Riccarton Avenue, Christchurch, 80 II,

New Zealand

Tel +6421750015

Fax +6433786080

Email yassar.alamri@nzbri.org
Advances in Medical Education and Practice 2021:12 189-194

DovePress in $\mathbf{D}$ 
being driven by external processes. The spectrum of EM varies according to the level of autonomy under which an action is undertaken; these vary from external regulation (doing an action for the pursuit of a reward), to introjected regulation (doing an action to comply with peer-pressure), to identified regulation (doing an action because it is seen as valuable), and lastly to integrated regulation (doing an action as it is perceived to enhance the doer's wellbeing). ${ }^{5}$ A common element to these graded regulations is an underlying motive that is external to the enjoyment brought on by the task itself, and are therefore considered sub-types of EM.

Traditionally, IM has been regarded as superior to EM because it results in the deepest learning and enhanced well-being sense. ${ }^{5}$ It is assumed that it is also likely to lead to a longer-term commitment to, or engagement in, a task. For instance, the use of monetary rewards to encourage resident research was criticised for reducing the research craft to an incentivised value, rather than promoting its noble quest of igniting scientific curiosity, and ultimately, the betterment of patient care. ${ }^{6}$

For medical students, the studies of motivation range from pre-matriculation stage to senior residency stage, and encompass a variety of areas (including research engagement by those students). For example, a recent study by Miyoshi et al found that a Japanese student's biggest motivation to matriculate in a medical course was intrinsic motivation (rather than family pressure or positive influence by a physician). ${ }^{7}$ Dutch medical students who scored higher on intrinsic (rather than extrinsic) motivation were more likely to be involved in research. ${ }^{8}$ Residents from a US institution who were promised monetary rewards were more likely to publish their research findings. ${ }^{9}$ Finally, UK junior doctors who were advised that completing a $\mathrm{PhD}$ would be required to enhance their career applications were more likely to pursue research/academic careers. ${ }^{10}$ There are thus conflicting effects from the type of motivation or engagement in research.

The aim of the present study, therefore, was to examine whether self-reported engagement in research by medical students differed based upon their expressed motivation. At our institution, the medical degree is taken over six years: pre-clinical "junior" phase (years 1,2 and 3), and a clinical "senior" phase (years 4, 5 and 6). Our a priori hypothesis was that extrinsic motivation towards undertaking research would be higher in senior medical students due to their temporal proximity to job/training position applications.

\section{Methods}

\section{Study Setting}

This was a cross-sectional study. Eligible participants were all medical students enrolled at the University of Otago, New Zealand during the 2019 academic year. Potential participants were contacted by the Manager of Student Affairs, and invited to complete an online survey. The survey was open for a 15week period (March-July 2019); five-weekly reminders were sent. The project was approved by the University of Otago Human Ethics Committee (reference D18/207). The STROBE guidelines ${ }^{11}$ have been used to report the results of this study.

\section{Data Measurement}

A survey was developed for the purposes of this study, and included questions about the students' demographics (age, sex, ethnicity and marital status), academic details (current year, route of medical school entry, and previous research degrees), and prior research experience (nature of previous experience, and academic output). To ascertain students' motivation, they were asked an open-ended question to describe the single major factor that would encourage them to get involved in research as medical students.

Based upon previous studies, ${ }^{7,8}$ we classified responses relating to the major factor encouraging research participation as IM if they included interest, passion, and enjoyment; and responses as EM if they related to financial gains, improving chances to gain entry to competitive post-graduate training, and publications/travel. Responses that mentioned both (e.g., interest and financial compensation) or neither (e.g., undertaking research due to being inspired by a specific mentor) were excluded (see Table 1 for response examples). Responses were categorised by the first author after consultation with the other co-authors. Therefore, the final sample size included all students whose responses fell into one of the two (intrinsic vs extrinsic) motivation groups.

\section{Outcomes}

Self-reported research engagement was the primary outcome. Research engagement was defined as undertaking an intercalated research degree (i.e., after enrolment in the medical degree) or voluntary substantial involvement (as defined by the International Committee of Medical Journal Editors ${ }^{12}$ ) in extra-curricular research projects. Prior degrees and compulsory research modules (e.g., lectures on evidence-based medicine, and group tasks to critique published articles) were excluded. Several predictors were considered, including the student's motivation (IM vs 
Table I Examples of Motivation Classification According to the Students' Responses to the Single Major Factor That Encouraged Them to Pursue Research Activities

\begin{tabular}{|l|l|l|}
\hline Responses Classified as "IM" & Responses Classified as “EM" & Excluded Responses \\
\hline "Genuine interest and inspiration" & "Good for the CV" & "Supportive supervisors" \\
\hline $\begin{array}{l}\text { "A topic [that the student is] passionate } \\
\text { about" }\end{array}$ & $\begin{array}{l}\text { "Easier entrance to [a surgical specialty] training } \\
\text { programme" }\end{array}$ & $\begin{array}{l}\text { "The ability to choose [student's] own } \\
\text { research topic" }\end{array}$ \\
\hline "Enjoyment" & "Compensation" & "Only if made compulsory" \\
\hline "Self-driven desire to learn" & "Publication points" & "Having time to do so" \\
\hline "Interest in the research process itself" & "Influence on job prospects" & "Experience research, and improve CV" \\
\hline
\end{tabular}

Abbreviations: EM, extrinsic motivation; IM, intrinsic motivation.

EM), age, sex, route of medical school entry, and prior research experience.

\section{Statistical Analysis}

Descriptive statistics were utilised to present most of the data (expressed as means $\pm \mathrm{SD}$, medians, or proportions). Odds ratios (OR), and associated $95 \%$ confidence intervals were calculated using binary regression analysis. All analyses were undertaken using SPSS Statistics ${ }^{\circledR}$ software package (version 22.0.0.0).

\section{Results}

\section{Study Participants}

Out of 1493 medical students, 685 returned the present survey (response rate $45.9 \%$ ). After excluding incomplete and duplicate surveys, 587 were included in the final analysis. See Figure 1 for details on the recruitment process.

The study sample was made up of 253 junior medical students (43.1\%), 10 intercalating medical students $(1.7 \%)$, and 323 senior medical students $(55 \%)$; one

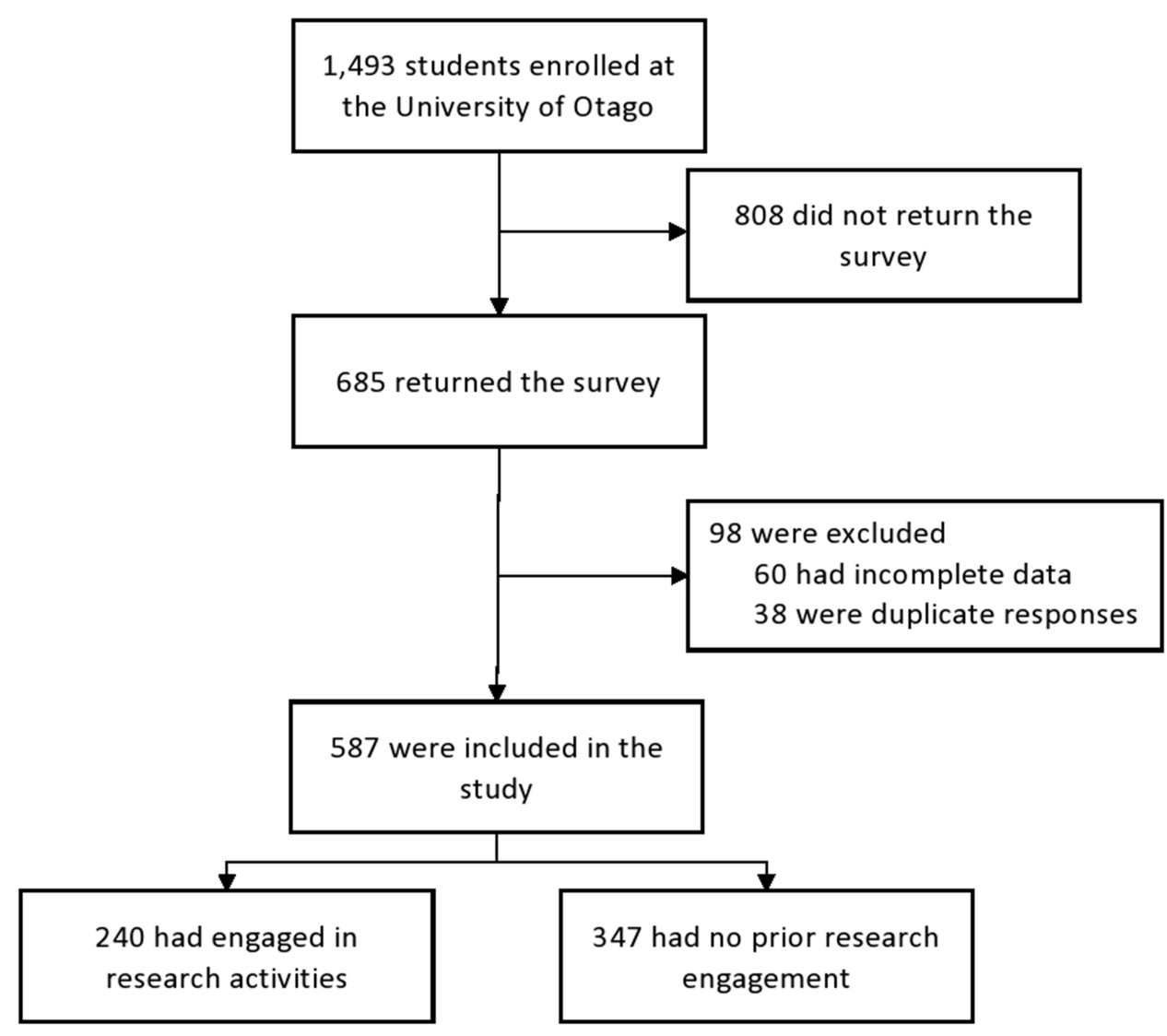

Figure I The recruitment process and study groups. 
student did not indicate their current level of study. The majority of the student respondents were female $(392 / 587$; $66.8 \%$ ), and the median age was 22 years (range, 18-52).

\section{Predictors of Research Engagement}

From the study sample, 240 medical students (40.9\%) indicated prior research engagement. Table 2 summarises the findings of the regression analysis. Completing a research degree prior to medical school was strongly predictive of research engagement during medical school. Additionally, students who engaged in research activities were significantly more likely to express EM as their major motive.

\section{Discussion}

The present study examined the effect of motivation on medical student engagement in research activities at our institution. Medical students who engaged in extracurricular research activities were more likely to be older, report EM, and have completed a prior research degree.

Female respondents made up the majority in this study (despite only comprising just over half of the medical school class ${ }^{13}$ ). How this affects our results remains unclear. The sex-specific role of motivation in the context of medical education has not been previously explored.

At first glance, our results appear to be contradictory to those from the only other study specifically addressing medical student motivation and research involvement. ${ }^{8}$ Whereas we found EM to be more strongly associated with research engagement, Ommering et $\mathrm{al}^{8}$ found IM to be a bigger driver. However, it is vital to note a key difference in study populations: first-year medical students in the study by Ommering et al, ${ }^{8}$ compared with all medical students in our study. It is possible some of the senior medical students in our sample were, at least partially, influenced by the looming deadline for intern position applications (a strong extrinsic motive to engage in research in order to "stand out"14). This may also explain why older students (i.e., more cognisant of career planning and job applications) were more likely to undertake extracurricular research activities. It is unclear as to whether the differences in the selection process for post-graduate training positions between New Zealand and the Netherlands (as an important external motivator for medical students to publish) could account for any of the differences observed between the two studies.

According to self-determination theory, ${ }^{4}$ essential to normal psychological health are the realisation of autonomy (self-control), competence (successful completion of a challenging task) and relatedness (personal connection with others). Undertaking a research activity can be seen as fulfilling these basic psychological needs: choosing a research topic of interest (i.e., autonomy), working with a research group (i.e., relatedness), and eventual publication of findings (competence). For a student with a strong extrinsic motive (e.g., obtaining a competitive surgical training position), it is conceivable that research involvement fulfils these basic psychological needs. It would be intriguing to examine the degree of research involvement in the EM cohort once their "reward" (e.g., successful entry into a competitive training programme) has been achieved.

In addition, there seems to be an overlap between a student's motivation for, and perception of research. ${ }^{15}$ Prior research has shown negative early research experiences and perceptions were associated with less future engagement in research. ${ }^{16,17}$ Similarly, positive research perceptions were associated with higher motivation for research. This intertwined relationship offers a fertile environment/impetus for educators/academic staff to capitalise on positive research perceptions among students, in order to stimulate intrinsic motivation and long-term involvement in academic pursuits. ${ }^{15}$

The present study has several limitations. A large number of responses were excluded as students had not either

Table 2 Binary Logistic Regression of Factors Associated with Research Engagement by Medical Students

\begin{tabular}{|l|l|l|l|l|}
\hline & Students Engaged in Research & Students Not Engaged in Research & OR (95\% CI) & P-value \\
\hline N (\%) & $240(40.9 \%)$ & $347(59.1 \%)$ & \\
Age (mean, years) & $23.7 \pm 3.5$ & $21.9 \pm 3.7$ & $1.11(1.03-1.19)$ & 0.005 \\
Sex (\% male) & $34 \%$ & $32 \%$ & $0.9(0.56-1.5)$ & 0.7 \\
Motivation (\% EM) & $48 \%$ & $36 \%$ & $1.63(1.04-2.57)$ & 0.03 \\
Entry route (\% postgraduate) & $34 \%$ & $19 \%$ & $1.02(0.6-1.73)$ & 1.0 \\
Previous research degree (\% yes) & $15 \%$ & $3 \%$ & $5.7(1.53-21.24)$ & 0.01 \\
\hline
\end{tabular}


type of motivation to be the major factor encouraging research engagement. The delineation of the two groups was based on the student's response to a single question (which, in turn, limits contextualising the responses). While recall bias cannot be excluded, it would have presumably affected both motivation groups. Ommering et al recently published a questionnaire that systematically scored medical students on IM and EM scales. ${ }^{4}$ However, the questionnaire has only been used to evaluate a cohort of junior Dutch medical students, and was available after the completion of data collection of the present study. Given the fact that the current study was conducted in a single institution, this limits its external generalisability.

\section{Conclusions}

From this cross-sectional study, we found students with higher EM were more likely to be involved in research, although the EM group was comparatively older, and had more pre-matriculation research experience compared with the IM group. Future studies should include longitudinal data in order to assess whether EM students continue to be involved in research long-term (as opposed to stopping once a "reward" is attained).

\section{Abbreviations}

IM, Intrinsic motivation; EM, extrinsic motivation; OR, odds ratio.

\section{Data Sharing Statement}

The datasets used and/or analysed during the current study are available from the corresponding author on reasonable request after completion of data publication.

\section{Ethics Approval and Consent to Participate}

This study was approved by the University of Otago Human Ethics Committee (reference D18/207). All participants provided consent (in written format) on the electronic survey form.

\section{Consent for Publication}

Participants provided written consent for anonymised data publication.

\section{Acknowledgments}

The authors would like to extend their gratitude to the Department of Psychological Medicine, University of
Otago, Christchurch, for their financial assistance with participant compensation. The Department had no involvement in the study otherwise.

\section{Author Contributions}

All authors made a significant contribution to the work reported, whether that is in the conception, study design, execution, acquisition of data, analysis and interpretation, or in all these areas; took part in drafting, revising or critically reviewing the article; gave final approval of the version to be published; have agreed on the journal to which the article has been submitted; and agree to be accountable for all aspects of the work.

\section{Funding}

The authors received $\$ 1500$ from the Department of Psychological Medicine, University of Otago (Christchurch, New Zealand), which were used to purchase $\$ 50$-gift vouchers given to 30 participants chosen at random.

\section{Disclosure}

The authors report no conflicts of interest in this work.

\section{References}

1. Alamri Y. Factors influencing decisions to become involved in research: a study of pre-clinical medical students from New Zealand. Med Sci Educ. 2019;29(2):489-492. doi:10.1007/s40670-019-00717-1

2. de Jong PGM, Haramati A. Teaching to develop scientific engagement in medical students. In: Huggett $\mathrm{KN}$, Jeffries WB, editors. An Introduction to Medical Teaching. Dordrecht: Springer Science + Business Media; 2014:12-14.

3. Wigfield A, Wentzel K. Introduction to motivation at school: interventions that work. Educ Psychol. 2007;42(4):191-196. doi:10.1080/ 00461520701621038

4. Deci EL, Ryan RM. The 'what' and 'why' of goal pursuits: human needs and the self-determination of behavior. Psychol Inq. 2000;11:227-268. doi:10.1207/S15327965PLI1104_01

5. Ryan RM, Deci EL. Self-determination theory and the facilitation of intrinsic motivation, social development, and well-being. Am Psychol. 2000;55:68-78. doi:10.1037/0003-066X.55.1.68

6. Fried MP. Resident, research, and rewards. JAMA Otolaryngol Head Neck Surg. 2014;140(5):479. doi:10.1001/jamaoto.2014.424

7. Miyoshi T, Uka M, Yano S, Asuka S, Hiroko O, Otsuka F. When do medical students aim to be a doctor in Japan? In: Proceedings of the Association for Medical Education in Europe (AMEE) conference; August, 2019; Vienna, Austria. Available from: https://amee.org/getat tachment/Conferences/AMEE-2019/AMEE-2019-Abstract-Book-v7. pdf. Accessed February 10, 2021.

8. Ommering BWC, van Blankenstein FM, Wijnen-Meijer M, et al. Fostering the physician-scientist workforce: a prospective cohort study to investigate the effect of undergraduate medical students' motivation for research on actual research involvement. BMJ Open. 2019;9(7):e028034. doi:10.1136/bmjopen-2018-028034 
9. Chang CW, Mills JC. Effects of a reward system on resident research productivity. JAMA Otolaryngol Head Neck Surg. 2013;139 (12):1285-1290. doi:10.1001/jamaoto.2013.5303

10. Ranieri VF, Barratt H, Rees G, Fulop NJ. A qualitative study of the influences on clinical academic physicians' postdoctoral career decision-making. Acad Med. 2018;93(11):1686-1693. doi:10.1097/ ACM.0000000000002141

11. von Elm E, Altman DG, Egger M, Pocock SJ, Gotzsche PC, Vandenbroucke JP. The Strengthening the Reporting of Observational Studies in Epidemiology (STROBE) statement: guidelines for reporting observational studies. Lancet. 2007;370 (9596):1453-1457. doi:10.1016/S0140-6736(07)61602-X

12. International Committee of Medical Journal Editors. Defining the role of authors and contributors. 2020. Available from: http://www.icmje. org/recommendations/browse/roles-and-responsibilities/defining-therole-of-authors-and-contributors.html. Accessed February 10, 2021.

13. Medical Deans Australia and New ZealandC. Student statistics report: 2017-2018. December, 2018. Available from: https://medical deans.org.au/md/2018/12/2018_Student_Statistics_Report.pdf. Accessed July 24, 2019.
14. Amgad M, Man Kin Tsui M, Liptrott SJ, Shash E, Manalo E. Medical student research: an integrated mixed-methods systematic review and meta-analysis. PLoS One. 2015;10(6):e0127470. doi:10.1371/journal. pone. 0127470

15. Ommering BWC, Wijnen-Meijer M, Dolmans DHJM, Dekker FW, van Blankenstein FM. Promoting positive perceptions of and motivation for research among undergraduate medical students to stimulate future research involvement: a grounded theory study. BMC Med Educ. 2020;20(1):204. doi:10.1186/s12909-020-02112-6

16. O'Sullivan PS, Niehaus B, Lockspeiser TM, et al. Becoming an academic doctor: perceptions of scholarly careers. Med Educ. 2009;43(4):335-341. doi:10.1111/j.1365-2923.2008.03270.x

17. Alamri Y, Al-Busaidi IS. Attitudes towards bullying may affect students' but not supervisors' future research involvement. Postgrad Med J. 2019;95(1124):347. doi:10.1136/postgradmedj-2018-136341

\section{Publish your work in this journal}

Advances in Medical Education and Practice is an international, peerreviewed, open access journal that aims to present and publish research on Medical Education covering medical, dental, nursing and allied health care professional education. The journal covers undergraduate education, postgraduate training and continuing medical education including emerging trends and innovative models linking education, research, and health care services. The manuscript management system is completely online and includes a very quick and fair peer-review system. Visit http://www.dovepress.com/testimonials.php to read real quotes from published authors. 